\title{
Cytotoxicity, Morphology and Chemical Composition of Two Luting Cements: An in Vitro Study
}

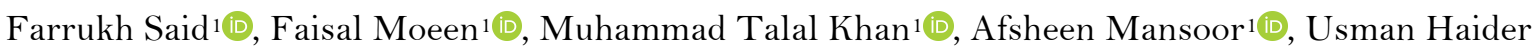

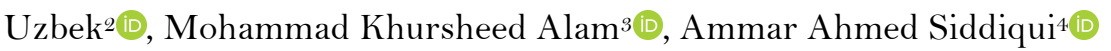

\begin{abstract}
'Department of Dental Materials, Islamic International Dental College, Islamabad, Pakistan. ${ }^{2}$ School of Dental Sciences, Universiti Sains Malaysia, Kubang Kerian, Kelantan, Malaysia.

${ }^{3}$ Department of Orthodontics, College of Dentistry, Jouf University, Sakaka, Kingdom of Saudi Arabia.

${ }^{4}$ Department of Preventive Dentistry, College of Dentistry, University of Hail, Hail, Kingdom of Saudi Arabia.
\end{abstract}

Author to whom correspondence should be addressed: Farrukh Said, Department of Dental Materials, Islamic International Dental College, 7th Avenue, Sector G-7/4, Islamabad, Pakistan. Phone: $+92 \quad 300911$ 0833. E-mail: drfarrukhsaid@gmail.com.

Academic Editors: Alessandro Leite Cavalcanti and Wilton Wilney Nascimento Padilha

Received: 05 December 2019 / Accepted: 27 February 2020 / Published: 03 March 2020

How to cite this article: Said F, Moeen F, Khan TM, Mansoor A, Uzbek UH, Alam MK, et al. Cytotoxicity, morphology and chemical composition of two luting cements: an in vitro study. Pesqui Bras Odontopediatria Clín Integr. 2020; 20:e5434. https://doi.org/10.1590/pboci.2020.041

\begin{abstract}
Objective: To assess the cytotoxicity, surface morphology, elemental compositions and chemical characterization of two commonly used luting cement. Material and Methods: The two luting types of cement used were Elite Cement ${ }^{\circledR}$ and Hy-Bond Resiglass ${ }^{\circledR}$. Freshly mixed $(n=6)$ and set form $(n=6)$ of each cement was placed in medium to obtain extracts. The extract from each sample was exposed to L929 mouse fibroblasts (1x104cells/well). Alamar Blue Assay assessed cell viability. Surface morphology and elemental composition were evaluated using scanning electron microscopy and energy dispersive spectroscopy. The chemical characterization was performed by Fourier Transform Infrared Spectroscopy. One-way ANOVA and post-hoc Tukey analysis were conducted to assess results. Results: Hy-Bond Resiglass ${ }^{\circledR}$ was the more cytotoxic of the two types of cement in both freshly mixed $(68.10+5.16 ; \mathrm{p}<0.05)$ and set state $(87.58+4.86$; $\mathrm{p}<0.05)$, compared to Elite Cement ${ }^{\circledR}$ both freshly mixed $(77.01+5.45 ; \mathrm{p}<0.05)$ and set state $(89.39+5.66$; $\mathrm{p}<0.05)$. Scanning electron microscopy revealed a more irregular and porous structure in Hy-Bond

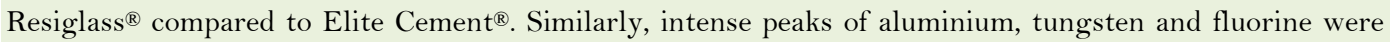
observed in energy dispersive spectroscopy in Hy-Bond Resiglass. Conclusion: All these three elements (aluminium, tungsten and fluorine) have cytotoxic potential. The Fourier transform infrared spectroscopy revealed the presence of hydroxyethyl methacrylate in Hy-Bond Resiglass ${ }^{\circledR}$, which has a cytotoxic potential.
\end{abstract}

Keywords: Dental Materials; Dental Cements; Zinc Phosphate Cement; Fibroblasts. 


\section{Introduction}

In clinical dentistry, luting cement are used for the purpose of sealing, cementing or bonding objects or particles together. By definition, it is the cement that holds a fix prosthesis, orthodontic appliances, post and core static, stable for a long period in the oral cavity. The retention mechanisms for this prosthesis can be micromechanical, mechanical and chemical. In most of the cases, a combination of two or three mechanisms are used for successful retention of the prosthesis. Ideally, these cements should be nontoxic, nonirritant, good mechanical properties, strong adhesion, excellent esthetics, radiopaque, resistant to caries and plaque accumulation, less soluble, antimicrobial, average film thickness and should possess a good sealing ability [1].

The biological compatibility with tooth vitality is an important factor that needs to be fulfilled. Cytotoxicity of any dental cement is an essential consideration because it may evoke a certain adverse reaction of allergic and/or toxic nature [2]. These can be from the chemical irritation of the materials and $\mathrm{pH}$ changes during setting reactions [3]. The acidic content of the cement is also a factor that may contribute or aggravate cytotoxic response; therefore, it is necessary to know the acidic potential of a cement. Dental cement releases different elements during and after setting; therefore, different biological responses are to be expected from different types of cement. Numerous studies focus on the cytotoxicity of dental materials with special regards to contact with soft tissue [4].

One of the oldest luting materials still in use today is Zinc phosphate [5]. It remains quite popular despite a documented track record of disadvantages such as increased solubility and low adhesion. In comparison, the most widely used luting material in modern dentistry is resin-modified glass ionomer cement. Despite a lot of improvements, cytotoxicity of the resin-based dental materials is still remains unsatisfactory and a challenge to deal with. Due to incomplete polymerization, there are unreacted ingredients of resin-based cement in the oral cavity and they are genotoxic and cytotoxic [6]. The resin-based materials contain monomers such as hydroxyethyl methacrylate (HEMA), bisphenol A-glycidyl methacrylate (Bis-GMA), triethylene glycol dimethacrylate (TEGDMA) and other initiating components. Due to the presence of HEMA and TEGDMA, cytotoxicity remains a considerable concern in the resin-based materials. The concentration and chemical structure of the monomer determines the cytotoxic properties of resin [7].

In this research, a comparative study and analysis were performed to monitor the changes in cell viability and metabolic activity to determine the cytotoxicity of the luting cement, followed by scanning electron microscopy with energy dispersive x-ray spectroscopy was to study surface morphology and elemental mapping of luting cement. Fourier transform infrared spectroscopy was performed for chemical characterization of the cement to list different possible components of the cement that may be responsible for the cytotoxic response.

\section{Material and Methods}

Materials and Sample Preparation

Elite Cement ${ }^{\circledR}$ (ZnPO4) and Hy-Bond Resiglass ${ }^{\circledR}$ (RMGIC) were used as per the manufacturer's instructions (Table 1). Both materials were mixed according to the instructions of manufacturers under a sterile condition. After mixing, cement was placed in a $5 \times 5 \mathrm{~mm}$ cylindrical Teflon mold [8]. Two forms of samples were prepared, freshly mixed and set state [9]. 
Table 1. Manufacturers and compositions of luting materials.

\begin{tabular}{|c|c|c|c|c|c|}
\hline Materials & Manufacturer & Composition & $\begin{array}{c}\text { Working } \\
\text { Time }\end{array}$ & $\begin{array}{c}\text { Setting } \\
\text { Time }\end{array}$ & $\begin{array}{c}\text { Excess } \\
\text { Removal }\end{array}$ \\
\hline $\begin{array}{c}\text { Elite } \\
\text { Cement }^{\circledR}\end{array}$ & $\begin{array}{c}\text { GC Corp., Ltd., } \\
\text { Tokyo Japan }\end{array}$ & $\begin{array}{l}\text { Powder: Zinc oxide, barium oxide } \\
\text { magnesium oxide, calcium oxide, silica } \\
\text { Liquid: Zinc phosphate, phosphoric acid, } \\
\text { aluminum, aluminum phosphate, water. }\end{array}$ & $\begin{array}{c}3 \text { to } 4 \\
\text { minutes }\end{array}$ & $\begin{array}{l}7 \text { minutes } \\
10 \text { seconds }\end{array}$ & Easy \\
\hline $\begin{array}{l}\text { Hy-Bond } \\
\text { Resiglass }^{\circledR}\end{array}$ & $\begin{array}{l}\text { Shofu Inc., } \\
\text { Kyoto Japan }\end{array}$ & $\begin{array}{l}\text { Powder: Polymerizable resin, ion leachable } \\
\text { glasses, chemical initiator, photoinitiator, } \\
\text { silica (Sio). } \\
\text { Liquid: Polyacrylic acid, methyl } \\
\text { methacrylate (MMA), water, hydroxyethyl } \\
\text { methacrylate (HEMA). }\end{array}$ & $\begin{array}{l}3 \text { minutes } \\
30 \text { seconds }\end{array}$ & 7 minutes & Difficult \\
\hline
\end{tabular}

Preparation of Luting Extract

Each fresh sample was subjected to Dulbecco's Modified Eagle's Medium (DMEM) by a surface-tovolume ratio of $1.25 \mathrm{~cm}^{2} / \mathrm{mL}$ [10]. The tubes were stored for $24 \mathrm{~h}$ at $37^{\circ} \mathrm{C}$. The extracts were collected after 24hours with a pipette (Eppendorf AG, Hamburg, Germany) and stored in sterile tubes (CO2 Incubator - Esco Micro Pte. Ltd., Singapore) [9].

Each set sample was subjected to Dulbecco's Modified Eagle’s Medium (DMEM) as per the surfaceto-volume ratio of $1.25 \mathrm{~cm}^{2} / \mathrm{mL}[10]$. The sample stored in extraction media was incubated for $24 \mathrm{~h}$ at $37^{\circ} \mathrm{C}$ [10]. After 24 hours, extracts were collected with a pipette and stored.

\section{Assessment of Cytotoxicity}

Cell Culture

L929 mouse fibroblasts from American Type Culture Collection (ATCC, VA, USA) were used for this study [11]. The cell was cultured using Dulbecco's Eagle modified medium (DMEM) supplemented with 10\% fetal bovine serum (FBS, Gibco, Grand Island, NY, USA), $100 \mathrm{ul} / \mathrm{mL}$ penicillin, $2.5 \mathrm{ug} / \mathrm{mL}$ streptomycin (Invitrogen, Thermo Fisher Scientific, Grand Island, NY, USA). The culture media was changed regularly twice a week and incubated in a humidified atmosphere with $5 \% \mathrm{CO} 2$ in air at $37^{\circ} \mathrm{C}$. After the cultured cells were allowed to proliferate and their adherence at a logarithmic phase was achieved, the cells were detached by trypsinization (0.02\% trypsin in $0.25 \%$ EDTA) [12]. The cells were suspended in a cell medium to activate trypsin [13]. The cells $\left(1 \times 104\right.$ cells $\left./ \mathrm{cm}^{2}\right)$ were seeded at in a 96 - well plate and cultured again for 2 days.

\section{Alamar Blue Assay}

The culture medium was drawn and the cells were subjected to $1 \mathrm{ul}$ of extraction media per well and incubated for 1, 3 and 7 days. After Day 1 extraction media was drawn and alamar blue reagent $10 \%$ was added in each well. After 4 hours of the incubation period, the fluorescence of each well was measured at an excitation wavelength of $530 \mathrm{~nm}$ and an emission wavelength of $590 \mathrm{~nm}$ by a fluorescence well plate reader (PR 4100, Bio-Rad Laboratories, Inc., CA, USA) [14]. Three wells per sample were used, and wells without luting cement extracts were used as a control group. The same procedures were used for days 3 and 7 .

Scanning Electron Microscope (SEM) and Energy Dispersive Spectroscopy (EDS)

The surface morphology of cement was analyzed by scanning electron microscope (TESCAN Brno s.r.o., Brno, Czech Republic) at an accelerating voltage of $20.0 \mathrm{KV}$. A working distance ranging from 14-15 $\mathrm{mm}$. The magnification employed was between $500 \mathrm{X}$ to $1 \mathrm{KX}[15]$. Energy dispersive spectroscopy was also 
performed for all the samples with VEGA3 SB (TESCAN Brno s.r.o., Brno, Czech Republic). The charged particles, which were bombarded from the emission of x-rays from the sample surface, were detected by energy dispersive spectroscopy. The aim of EDS was to evaluate the chemical composition of the sample. Thus making it possible to know elements that constitute more than $0.1 \%$ of the material [15].

Fourier Transform Infrared Spectroscopy (FTIR)

Nicolet 6700 FT-IR spectrometer (Thermo Fisher Scientific, Grand Island, NY, USA) was used to collect FTIR spectra of all samples. It was equipped with attenuated total reflectance (ATR) and a photoacoustic sampling cell (PAS cell, Mtech Corporation). The PAS cell's sample chamber was cleaned by dry helium gas. In the case of ATR, samples were placed directly in contact with ATR diamond crystal. The spectra for all the samples were collected between spectral ranges of 4,000-400 $\mathrm{cm}^{-1}$. The measurements of all the spectra were at $8 \mathrm{~cm}^{-1}$ resolution accumulating a total of 256 numbers of scans [16].

\section{Data Analysis}

The data were inserted in SPSS 20 software (IBM Corp., Armonk, NY, USA). In order to assess two different cement groups, one-way ANOVA and post-hoc Tukey analysis were conducted. The level of significance was set at $5 \%$.

\section{Results}

The control group maintained a survival rate of 100\% across all days. Set cement had a higher survival rate, in comparison to their fresh state. On day 1, a fresh state of Hy-Bond Resiglass $(75.738+6.915)$ had a higher cell survival rate as compared with Elite Cement $(44.88+2.690)$. Similarly, on day 3 , the higher cell survival rate was observed in Hy-Bond Resiglass $(75.93+4.77)$ than Elite cement $(68.30+5.984)$. Cytotoxicity analysis of the fresh luting cement on day 7 revealed a significant difference between the control group and both types of cement. The cell survival rate was better in Elite Cement $(77.01+5.456)$ then HyBond Resilglass $(68.10+5.161)$.

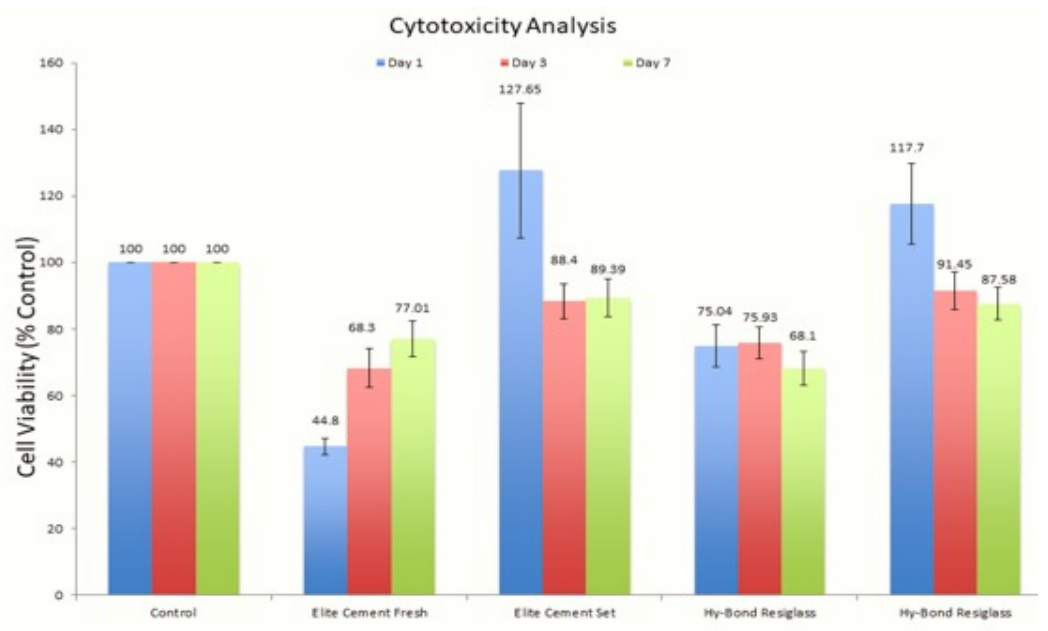

Figure 1. Cytotoxic analysis at days 1, 3, and 7 .

Both types of cement had a greater survival rate than the control group in their set state on day 1. The cell survival rate observed was higher in Elite Cement $(127.65+22.21)$, followed by Hy-Bond Resiglass 
$(117.70+13.30)$. However, the order was reversed on day 3, and the cell survival rate was in following order Hy-Bond Resiglass $(91.45+5.629)$ and Elite Cement $(88.40+5.22)$. On day 7 in their set state, both types of cement had significantly lesser survival rates than the Control group. The cell survival rate was in the following order Elite Cement $(89.39+5.669)$ and Hy-Bond Resiglass $(87.58+4.866)$.

SEM images of Elite cement revealed an irregular structure with evenly distributed particles (Figure 2A). Pores of variable sizes were observed at higher magnifications. At higher magnifications, cracks were observed in the structure of Elite Cement (Figure $2 \mathrm{~A}$ and B). The EDS analysis of Elite Cement revealed an intense peak of zinc due to the presence of zinc oxide in its composition. Similarly, an intense peak of phosphorus was observed due to the presence of phosphoric acid, zinc phosphate and aluminium phosphate. (Figure 2C).

Irregularly shaped particles were observed throughout the structure of Hy-Bond Resiglass (Figure 2D). At higher magnifications, pores of variable sizes were also found in the cement (Figure $2 \mathrm{E}$ ). Intense peaks of tungsten, fluorine and aluminium were observed in the EDS spectrum of Hy-Bond Resiglass (Figure $2 \mathrm{~F}$ ).

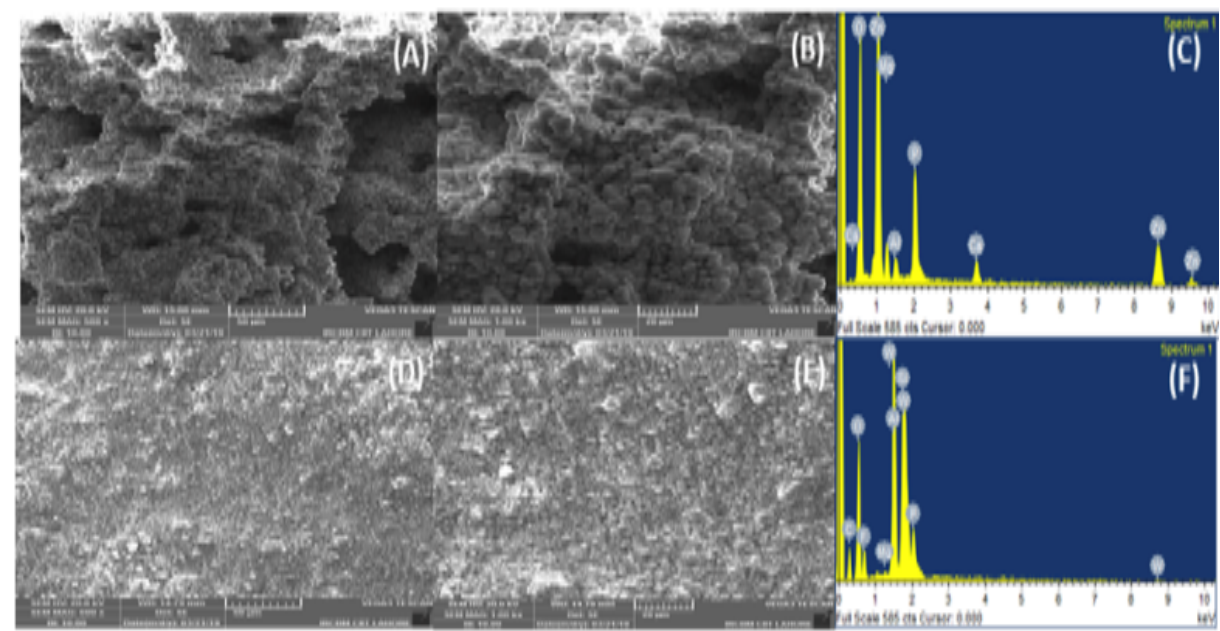

Figure 2. SEM with EDS for luting cements.

FTIR Interpretations

The spectrum of freshly mixed Elite Cement revealed a stretching vibration of $\mathrm{P}-\mathrm{O}$ at a wavelength of $1042 \mathrm{~cm}^{-1}$. In the set form of Elite Cement spectrum, a strong, broad stretching peak at $1047 \mathrm{~cm}^{-1}$ and 1044 $\mathrm{cm}^{-1}$ were noticed (Figure 3A). In the spectrum of freshly mixed Hy-bond Resiglass a medium, sharp peak with an $\mathrm{O}-\mathrm{H}$ bond was observed. However, in a set form of Hy-Bond Resiglass, a sharp peak with the O-H bond was observed at $3700 \mathrm{~cm}^{-1}$ (Figure $\left.3 \mathrm{~B}\right)$. Table 2 shows the presence of chemical groups in luting cement along with their wavelength and absorbance.

Table 2. Wavelength and absorbance of groups in luting cements.

\begin{tabular}{lcccc}
\hline Peaks & \multicolumn{2}{c}{ Freshly Mixed } & \multicolumn{2}{c}{ Set Form } \\
& Wavenumber $\mathrm{cm}^{-1}$ & Absorbance & Wavenumber cm-1 & Absorbance \\
\hline & $3735 \mathrm{~cm}^{-1}$ & Elite Cement & \\
O-H & -0.010 & $3735 \mathrm{~cm}^{-1}$ & -0.021 \\
$\mathrm{H}-\mathrm{O}-\mathrm{H}$ & $1717 \mathrm{~cm}^{-1}$ & -0.035 & $1717 \mathrm{~cm}^{-1}$ & -0.020 \\
P-O & $1047 \mathrm{~cm}^{-1}$ & -0.011 & $1047 \mathrm{~cm}^{-1}$ & 0.025 \\
CO-O-CO & $1044 \mathrm{~cm}^{-1}$ & -0.010 & $1044 \mathrm{~cm}^{-1}$ & 0.026
\end{tabular}




\begin{tabular}{lcccc} 
& \multicolumn{3}{c}{ Hy-bond Resiglass } \\
$\mathrm{O}-\mathrm{H}$ & $3700 \mathrm{~cm}^{-1}$ & 0.0262 & $3700 \mathrm{~cm}^{-1}$ & -0.0280 \\
$\mathrm{C}=\mathrm{O}$ & $1701 \mathrm{~cm}^{-1}$ & 0.331 & $1701 \mathrm{~cm}^{-1}$ & -0.025 \\
$\mathrm{C}-\mathrm{H}$ & $1484 \mathrm{~cm}^{-1}$ & 0.073 & $1484 \mathrm{~cm}^{-1}$ & -0.027 \\
$\mathrm{C}-\mathrm{O}-\mathrm{C}$ & $1032 \mathrm{~cm}^{-1}$ & 0.550 & $1032 \mathrm{~cm}^{-1}$ & -0.006 \\
\hline
\end{tabular}

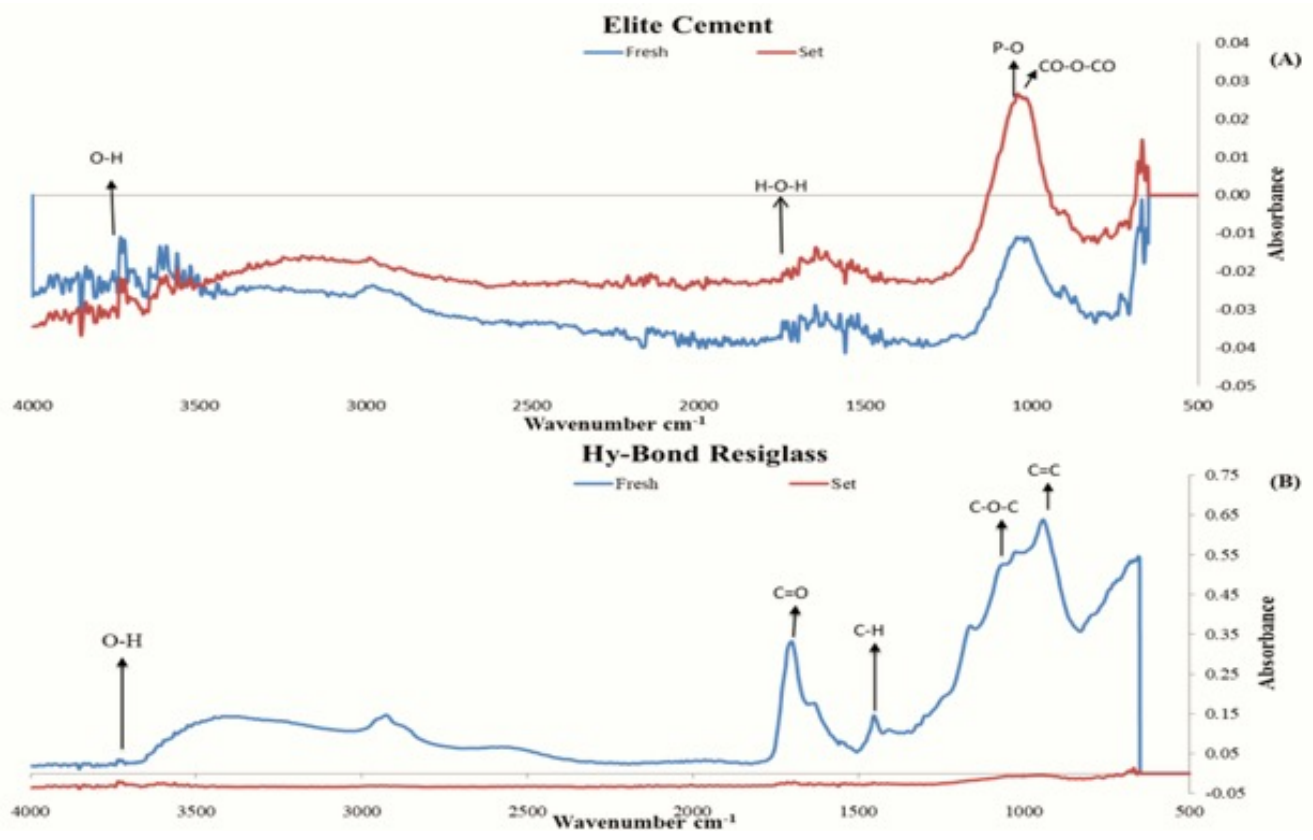

Figure 3. FTIR for luting cements.

\section{Discussion}

The main goal of our study was to compare the cytotoxicity of two luting cement. These cements were compared with a control group. The control group maintained a survival rate of $100 \%$ across all days. Set cement in both cases had a greater survival rate in comparison to the cement in their fresh state. The alamar blue assay was used for cell survival rate analysis. The readings were taken on days 1, 3, and 7 for the freshly mixed form and set the state of the materials.

On days 1 and 3, there was a significant difference in cell survival rate for both types of cement in their fresh state. Elite cement was found more cytotoxic as compared with Hy-Bond Resiglass cement. However, the trend was opposite on Day 7, as the cell survival rate was less in Hy-Bond Resiglass as compared with Elite cement. In their set state, there was a decreasing trend in both types of cement as the days progressed. At the end of Day 7, the cell survival rate was less in Hy-Bond Resiglass in comparison with Elite cement.

This study concluded that both luting cement has the potential to trigger adverse biological responses. The gingival and pulpal cells can be affected by certain elements released from the cement. The amount of zinc released from zinc phosphate released will determine its cytotoxicity. On the other hand, factors such as BIS- GMA, TEG-DMA, unbound free monomer and HEMA release during and post-polymerization, are also contributing factors for cytotoxicity.

The scanning electron microscopy results revealed that Hy-Bond Resiglass exhibit more irregular structure as compared with Elite Cement. This irregular structure may create cracks and provide a larger surface area then a spherical structure. Both factors will not cause only accelerated degradation but may also 
cause the quick release of cytotoxic elements from the cement [17]. A high peak of zinc and phosphorus was observed in the EDS spectrum of Elite cement. In a previous study on different dental materials for the evaluation of chemical elements composition using a scanning electron microscope and energy-dispersive x-ray spectroscopy. It was observed that zinc has a cytotoxic potential [18]. Intense peaks of tungsten (W), fluorine (F) and aluminium (Al) were observed in the EDS spectrum of Hy-bond Resiglass. An earlier study conducted on the elemental composition of different dental materials suggested that aluminium and tungsten both have the potential of cytotoxicity [18].

The FTIR spectrum of Elite Cement revealed two peaks at a wavelength of $1044 \mathrm{~cm}^{-1}$ and $1047 \mathrm{~cm}^{-1}$. In a previous study, FTIR spectrum of zinc phosphate cement revealed peaks of P-O between $1040 \mathrm{~cm}^{-1}-1110$ $\mathrm{cm}^{-1}[16]$. These peaks revealed the presence of stretching vibrations of $\mathrm{P}-\mathrm{O}$ in zinc phosphate cement. The presence of P-O may be due to phosphoric acid, and aluminium phosphate, both phosphoric acid and aluminium phosphate have a cytotoxic potential [18,19]. In another study, a peak of $\mathrm{P}-\mathrm{O}$ bond at $1050 \mathrm{~cm}^{-1}$ in a spectrum of zinc phosphate cement was observed, revealing the presence of phosphoric acid or aluminium phosphate [20]. In Fourier transform infrared spectrum of Hy-Bond Resiglass a medium, sharp peak at $3700 \mathrm{~cm}^{-1}$ with $\mathrm{O}-\mathrm{H}$ bond was observed. The presence of $\mathrm{O}-\mathrm{H}$ peaks between $3300 \mathrm{~cm}^{-1}$ to $3700 \mathrm{~cm}^{-1}$ indicates hydrogen bonding in the material, which confirms the presence of HEMA in the material that is a cytotoxic material. In a previous study FTIR spectrum of HEMA revealed an $\mathrm{O}-\mathrm{H}$ peak between $3300 \mathrm{~cm}^{-1}-3700 \mathrm{~cm}^{-1}$ as well $[21]$.

\section{Conclusion}

Both cements exhibit cytotoxic potential in freshly mixed as well as the set state. However, the cell survival rate was higher in the set state then freshly mixed form. Hy-Bond Resiglass had had less cell survival in both freshly mixed and set state in comparison with Elite Cement. Hy-Bond Resiglass had a more irregular structure as well as more cytotoxic elements in it. Similarly, FTIR confirms certain bonds in Hy-Bond Resiglass that are potentially cytotoxic.

\section{Authors' Contributions}

\begin{tabular}{|c|c|c|}
\hline FS & (iD) $0000-0003-3112-4375$ & $\begin{array}{l}\text { Conceptualization, Methodology, Formal Analysis, Investigation, Writing - } \\
\text { Original Draft Preparation and Writing - Review and Editing. }\end{array}$ \\
\hline $\mathrm{FM}$ & (iD) $0000-0003-0265-1563$ & $\begin{array}{l}\text { Conceptualization, Methodology, Formal Analysis, Investigation, Writing - } \\
\text { Original Draft Preparation and Writing - Review and Editing. }\end{array}$ \\
\hline MTK & (iD) $0000-0002-6961-724 \mathrm{X}$ & $\begin{array}{l}\text { Conceptualization, Methodology, Formal Analysis, Investigation, Writing - } \\
\text { Original Draft Preparation and Writing - Review and Editing. }\end{array}$ \\
\hline AM & (iD) $0000-0002-1666-2987$ & $\begin{array}{l}\text { Conceptualization, Methodology, Investigation, Writing - Original Draft } \\
\text { Preparation and Writing - Review and Editing. }\end{array}$ \\
\hline UHU & (iD) $0000-0002-5226-5348$ & $\begin{array}{l}\text { Conceptualization, Writing - Original Draft Preparation and Writing - Review } \\
\text { and Editing. }\end{array}$ \\
\hline MKA & (iD) $0000-0001-7131-1752$ & $\begin{array}{l}\text { Conceptualization, Writing - Original Draft Preparation and Writing - Review } \\
\text { and Editing. }\end{array}$ \\
\hline AAS & (iD) $0000-0002-8816-6421$ & $\begin{array}{l}\text { Conceptualization, Writing - Original Draft Preparation and Writing - Review } \\
\text { and Editing. }\end{array}$ \\
\hline
\end{tabular}

\section{Financial Support}

None. 


\section{Conflict of Interest}

The authors declare no conflicts of interest.

\section{References}

[1] de la Macorra JC, Pradíes G. Conventional and adhesive luting cements. Clin Oral Investig 2002; 6(4):198-204. https://doi.org/10.1007/s00784-002-0184-1

[2] Schmid-Schwap M, Franz A, König F, Bristela M, Lucas T, Piehslinger E, et al. Cytotoxicity of four categories of dental cements. Dent Mater 2009; 25(3):360-8. https://doi.org/10.1016/j.dental.2008.08.002

[3] Smith DC, Ruse ND. Acidity of glass ionomer cements during setting and its relation to pulp sensitivity. J Am Dent Assoc 1986; 112(5):654-7. https://doi.org/10.14219/jada.archive.1986.0069

[4] Trumpaite-Vanagiene R, Bukelskiene V, Aleksejuniene J, Puriene A, Baltriukiene D, Rutkunas V. Cytotoxicity of commonly used luting cements - an in vitro study. Dent Mater J 2015; 34(3):294-301. https://doi.org/10.4012/dmj.2014-185

[5] Lad PP, Kamath M, Tarale K, Kusugal PB. Practical clinical considerations of luting cements: a review. J Int Oral Health 2014; 6(1):116-20.

[6] Schweikl H, Spagnuolo G, Schmalz G. Genetic and cellular toxicology of dental resin monomers. J Dent Res 2006; 85(10):870-7. https://doi.org/10.1177/154405910608501001

[7] Issa Y, Watts DC, Brunton PA, Waters CM, Duxbury AJ. Resin composite monomers alter MTT and LDH activity of human gingival fibroblasts in vitro. Dent Mater 2004; 20(1):12-20. https://doi.org/10.1016/s0109-5641(03)00053-8

[8] Pawińska M, Łuczaj-Cepowicz E, Kierklo A, Marczuk-Kolada G, Hołownia A. Assessment of cytotoxic potential of root canal sealers after hardening - an ex vivo study. Postepy Hig Med Dosw 2015; 69:503-9. https://doi.org/10.5604/17322693.1150134

[9] Jung S, Sielker S, Hanisch MR, Libricht V, Schäfer E, Dammaschke T. Cytotoxic effects of four different root canal sealers on human osteoblasts. PLoS One 2018; 13(3):e0194467. https://doi.org/10.1371/journal.pone.0194467

[10] Poggio C, Riva P, Chiesa M, Colombo M, Pietrocola G. Comparative cytotoxicity evaluation of eight root canal sealers. J Clin Exp Dent 2017; 9(4):e574-e578. https://doi.org/10.4317/jced.53724

[11] Kwon JS, Illeperuma RP, Kim J, Kim KM, Kim KN. Cytotoxicity evaluation of zinc oxide-eugenol and non-eugenol cements using different fibroblast cell lines. Acta Odontol Scand 2014; 72(1):64-70. https://doi.org/10.3109/00016357.2013.798871

[12] Wendt SL Jr, Ziemiecki TL, Spangberg LS. Indirect cytotoxic evaluation of dental materials. Oral Surg Oral Med Oral Pathol. 1993; 75(3):353-6. https://doi.org/10.1016/0030-4220(93)90150-3

[13] Konjhodzic-Prcic A, Jakupovic S, Hasic-Brankovic L, Vukovic A. Evaluation of biocompatibility of root canal sealers on L929 fibroblasts with multiscan EX spectrophotometer. Acta Inform Med 2015; 23(3):135-7. https://doi.org/10.5455/aim.2015.23.135-137

[14] Alsubait SA, Al Ajlan R, Mitwalli H, Aburaisi N, Mahmood A, Muthurangan M, et al. Cytotoxicity of different concentrations of three root canal sealers on human mesenchymal stem cells. Biomolecules 2018; 8(3):E68. https://doi.org/10.3390/biom8030068

[15] Dumas V, Rattner A, Vico L, Audouard E, Dumas JC, Naisson P, et al. Multiscale grooved titanium processed with femtosecond laser influences mesenchymal stem cell morphology, adhesion, and matrix organization. J Biomed Mater Res A 2012; 100(11):3108-16. https://doi.org/10.1002/jbm.a.34239

[16] Khan AS, Khalid H, Sarfraz Z, Khan M, Iqbal J, Muhammad M, et al. Vibrational spectroscopy of selective dental restorative materials. Appl Spectros Rev 2016; 52(6):507-40. https://doi.org/10.1080/05704928.2016.1244069

[17] Cifuentes SC, Gavilán R, Lieblich M, Benavente R, González-Carrasco JL. In vitro degradation of biodegradable polylactic acid/magnesium composites: relevance of $\mathrm{Mg}$ particle shape. Acta Biomater 2016; 32:348-57. https://doi.org/10.1016/j.actbio.2015.12.037

[18] Sampaio FC, Alencar AH, Guedes OA, Veloso HH, Santos TO, Estrela C. Chemical elements characterization of root canal sealers using scanning electron microscopy and energy dispersive x-ray analysis. Oral Health Dent Manag 2014; 13(1):27-34.

[19] Prado M, Silva EJNL, Duque TM, Zaia AA, Ferraz CCR, Almeida JFA, et al. Antimicrobial and cytotoxic effects of phosphoric acid solution compared to other root canal irrigants. J Appl Oral Sci 2015; 23(2):158-63. https://doi.org/10.1590/1678-775720130691

[20] Younas B, Khan AB, Muzaffar D, Hussain I, Chaudhry AA, Rehman IU. In situ reaction kinetic analysis of dental restorative materials. Eur Phys J Appl Phys 2013; 64(3):30701. https://doi.org/10.1051/epjap/2013130361

[21] Vargün E, Usanmaz A. Degradation of poly (2-hydroxyethyl methacrylate) obtained by radiation in aqueous solution. J Macromol Sci Part A Pure Appl Chem 2010; 47(9):882-91. https://doi.org/10.1080/10601325.2010.501304 